\title{
AUTOMATE MACHINE FOR RESCUE OPERATION FOR CHILD
}

\author{
Shah Vrunda $\mathbf{R}^{1}$, Chirag S Dalal ${ }^{2}$, Rajeev Dubey ${ }^{3}$ \\ ${ }^{1}$ M.Tech Scholer, Dept. of IC, Dharamsinh Desai University, Nadiad, Gujarat, India \\ ${ }^{2}$ Associate Professor, Dept. of IC, Dharamsinh Desai University, Nadiad, Gujarat, India \\ ${ }^{3}$ Managing Director, Quantum Age Tech Solutions Pvt. Ltd, Gujarat, India
}

\begin{abstract}
The aim of the project is to rescue of trapped child in to the boar well by continues monitoring \& supply of necessary items to survive using technical method. These bore wells in turn have started to take many innocent lives. Bores which yielded water and subsequently got depleted are left uncovered. Small children without noticing the hole dug for the bore well slip in and get trapped. To aid in such rescue we have proposed a system. The Methods to keep a child alive in a bore should take in to consideration the lack of oxygen, increased temperatures and humidity, which produces hyperthermia. These problems are addressed with fresh air delivery with or without oxygen. A hand-powered equipment to deliver fresh air inside bore is being designed. This method brings down temperature and delivers fresh air. Visualizing the child is made possible with infrared waterproof cameras and a portable high resolution TV Monitor. This is light weight machine that will go down into the bore well pipe and save the child life systematically. This machine will go down the bore well and perform the action. This robot type machine can stay alive trapped body from bore well until parallel hall will be dug up which will work as minimum amount of time and save the child life systematically.
\end{abstract}

Keywords: human control machine, hand power equipment, infrared camera, oxygen controlling system, labview software

\section{INTRODUCTION}

Bores which yielded water and subsequently got depleted are left uncovered. There were so many child deaths due to the open bore-wells. The children fell into the open borewells and the rescue operation was almost end with failure. In the present what we do is dig a new well of the same depth next to the bore well and then make a tunnel connecting the two. This is a time consuming and costly process. It may take hours or even days to dig new well.

There is no proper technique to rescue victims of such accidents. When the local arrangements do not work, Army is called for. In most cases reported so far, a parallel hole is dug up and then a horizontal path is made to reach to the subject's body. It is not only a time taking process, but also risky in various ways. Moreover it involves a lot of energy and expensive resources which are not easily available everywhere and in this process we always need big space around the trapped bore that we can dig a parallel bore.

To overcome these hurdles, we have designed a bore-well recue machine with advanced equipment and devices. This machine is a human controlled computerized machine system with additional safety devices. I have selected the particular area where I can move my work forward for rescue operation.Then I am planning for an approach to design a life saving machine which is totally save life to the trapped child. After studying all the cases we found a serious issue to do, to made a such robotic machine which can go through the trapped bore well without any support and grasp the trapped body in least minimum time with providing facilities of oxygen cylinder, food support, water supply system, microphone, infra red LED, speaker, LCD screen. With this machine, there is no chance of damaging human body and other minor damages, and we called that machine as "Bore Well Child Saver Machine". In this alternative scenario, there will be no requirement of digging any hole parallel to the bore-well. The remotely controlled robot will go down the bore well and perform the action. A lot of other hassles will also be avoided by this alternative technique. 


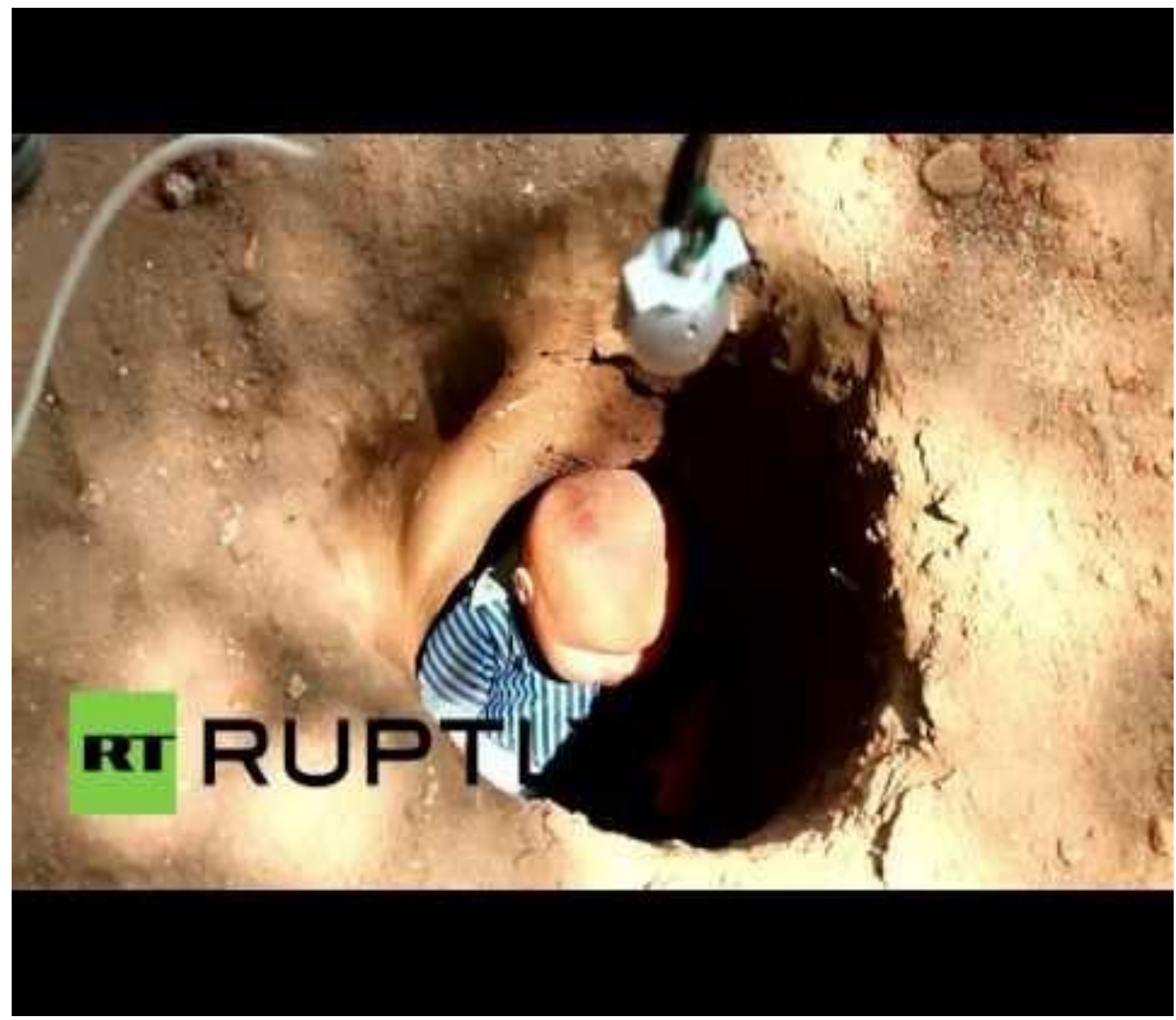

Fig -1: Image of a baby fell into borehole

\section{SYSTEM DESCRIPTIONS}

\subsection{Design Objectives}

Following are the design objectives of proposed system:

1) Supplying oxygen to the victim trapped inside the bore well.

2) Supplying water $\&$ food to the victim trapped inside the boar well

3) Safely machine is falling down without slipping in between and save the child life systematically

4) Taking out the victim safely as fast as possible.

\section{LITERAURE REVIEW}

\subsection{Current Existing System \& Why Rescue}

\section{Operation is Almost Fail to Save Child Life}

In Recent times in India many innocent children lost their lives to frequently occurring bore well accidents.

\section{Difficulties of Conventional Method of Rescuing}

It takes up to 30 hours to dig the parallel pit, by that time the child would have died.
- Lack of visualization causes the major difficulty during the rescue operation.

- There is no such special equipment for rescuing the child trapped inside the bore well.

- There is no proper technique to rescue victims of such accidents.

- When the make shift local arrangements do not work, Army is called in. In most cases reported so far, a parallel hole is dug up and then a horizontal path is made to reach to the subject's body.

- It is not only a time taking process, but also risky in various ways.

- Moreover it involves a lot of energy and expensive resources which are not easily available everywhere and in this process

- we always need big space around the trapped bore that we can dig a parallel bore.

- $\quad$ Lack of oxygen inside the bore well. 


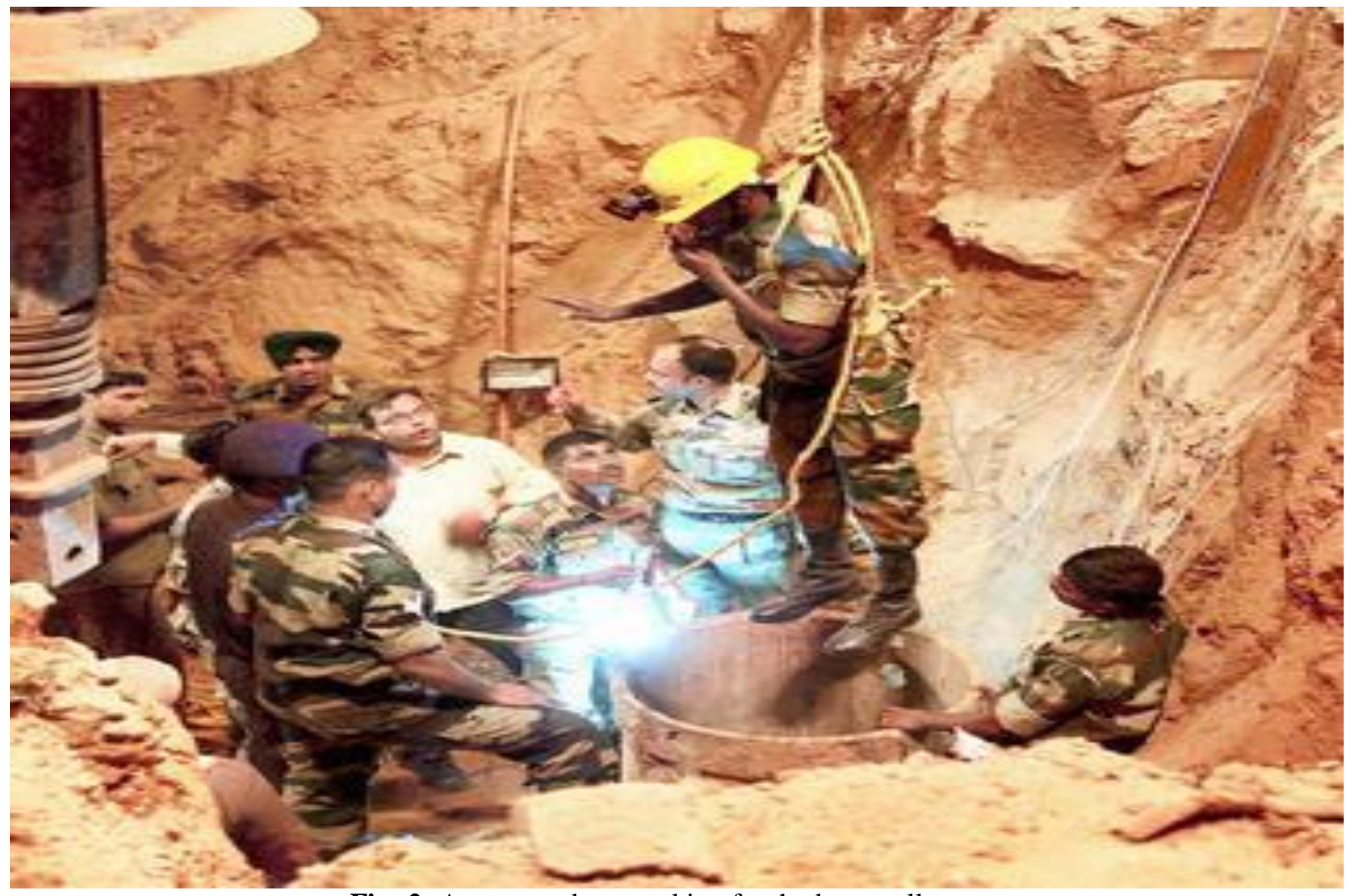

Fig -2: Army members working for the boar well rescue

\subsection{Possible Alternative Solutions}

To overcome such problems of these rescue operations, we have an alternative (feasible) proposal .I have select the particular area where I can move my work forward for rescue operation. Then I will approach to design a life saving machine which is totally save life to the trapped child. This project contains three different sections.

1. Communication

2. Life support

3. Extraction

I am able to work in this communication \&life support area.

\section{PROPOSED SYSTEM}

An Approach to Design of Child Saver Machine for Child Trapped in Borehole.

\subsection{System Operating Principal}

To rescue of trapped child in to the boar well by continues monitoring \& supply of necessary items to survive using technical method.

\subsection{Design Criteria}

To design rescue machine for saving people trapped in bore wells, following three criteria are considered:

1. Supplying oxygen to the victim trapped inside the bore well.

2. Supplying water $\&$ food to the victim trapped inside the boar well
3. Safely machine is falling down without slipping in between and save the child life systematically

4. Talking out the victim safely as fast as possible.

\subsection{Mechanism}

The machine is expected to be fabricated in such a way that the trained operator opens the stand and fixes over the bore well and give the input regarding depth and diameter of the bore well.

1) The machine self-operating system starts with the given input into the well. The IR sensor place along with camera on the bottom will detect the distance of the victim from the ground. Then the rescue machine is going to fit in the bore well.

2) Oxygen supply is provided through a special pipe arranged from the rescue machine. The rescue machine is going to sense the position of the person or child and it is going to send a long assisting pipe so that child can mount on them.

3) The assembly of machine is such a way that it has three degrees of freedom and can adjust its position according to safety and comfort of child.

4) Rapid bore well accidents prevailed in India during $2000-10$ to prevent the children fell into unclosed bore wells reducing the technical and financial risks involved in rescue operation and to perform the rescue operation in life saving operation for trapped child. 


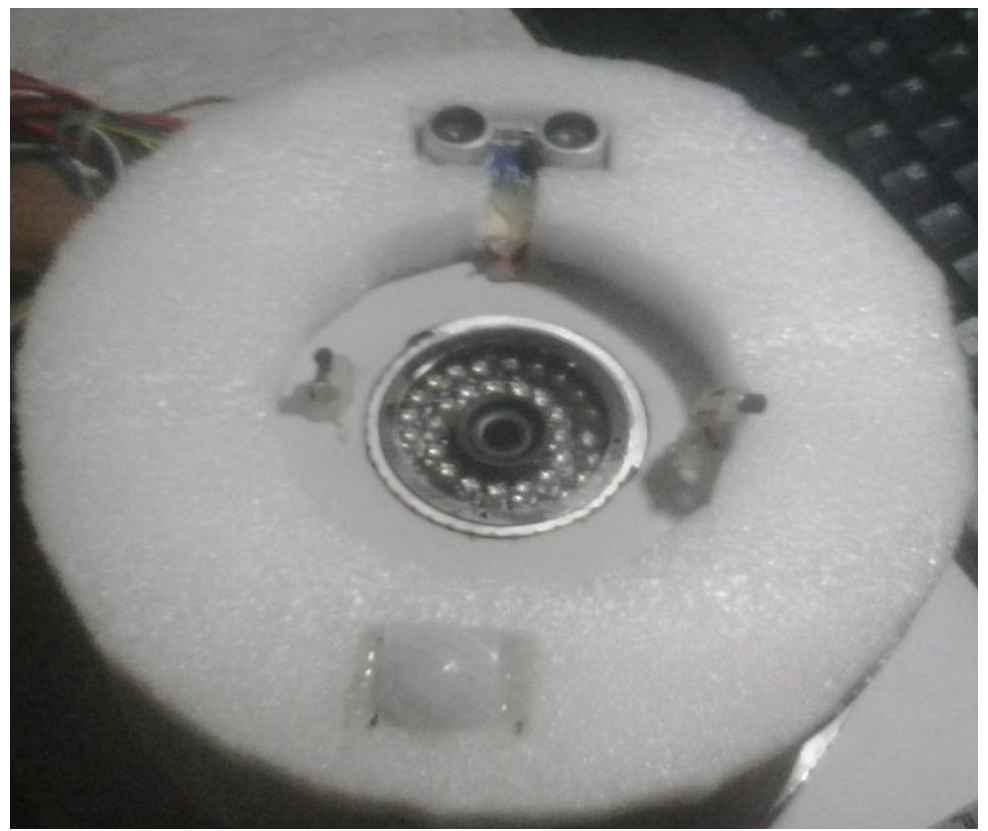

Fig- 3: Design concept

5) The basic concept of this project is to bring the victim to ground without any injuries in a very short span. This could be achieved by the advanced ergonomic design involved in the machine.

6) It seeks to harmonize the functionality of tasks with the human requirements of those performing them. Ergonomic design focuses on the compatibility of objects and environments with the humans using them

7) The aim of the first two steps is to make safe and sophisticated rescue machine. After making the concept ready, further design and modelling were carried out

\subsection{Schematic Diagram for Child Sever Machine}

Guide the Camera attached with the wire into the well carefully, till it reaches the child, watching the monitor carefully. Guide the 12' long pipe attached to the blower in to the well and admit fresh air into the well. Continues gives oxygen supply to the child.

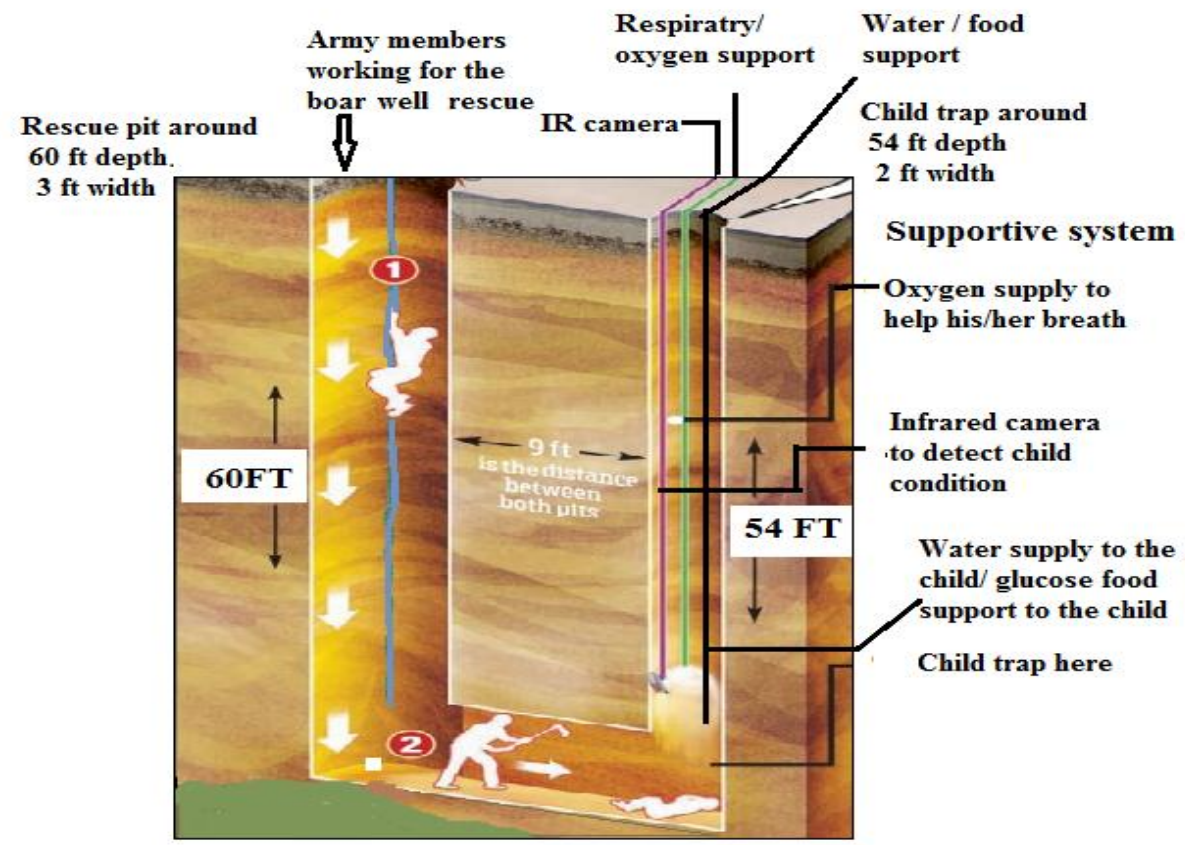

Fig- 4 Schematic Diagram for child sever machine 


\subsection{Hardware Approach for Rescue Operation}

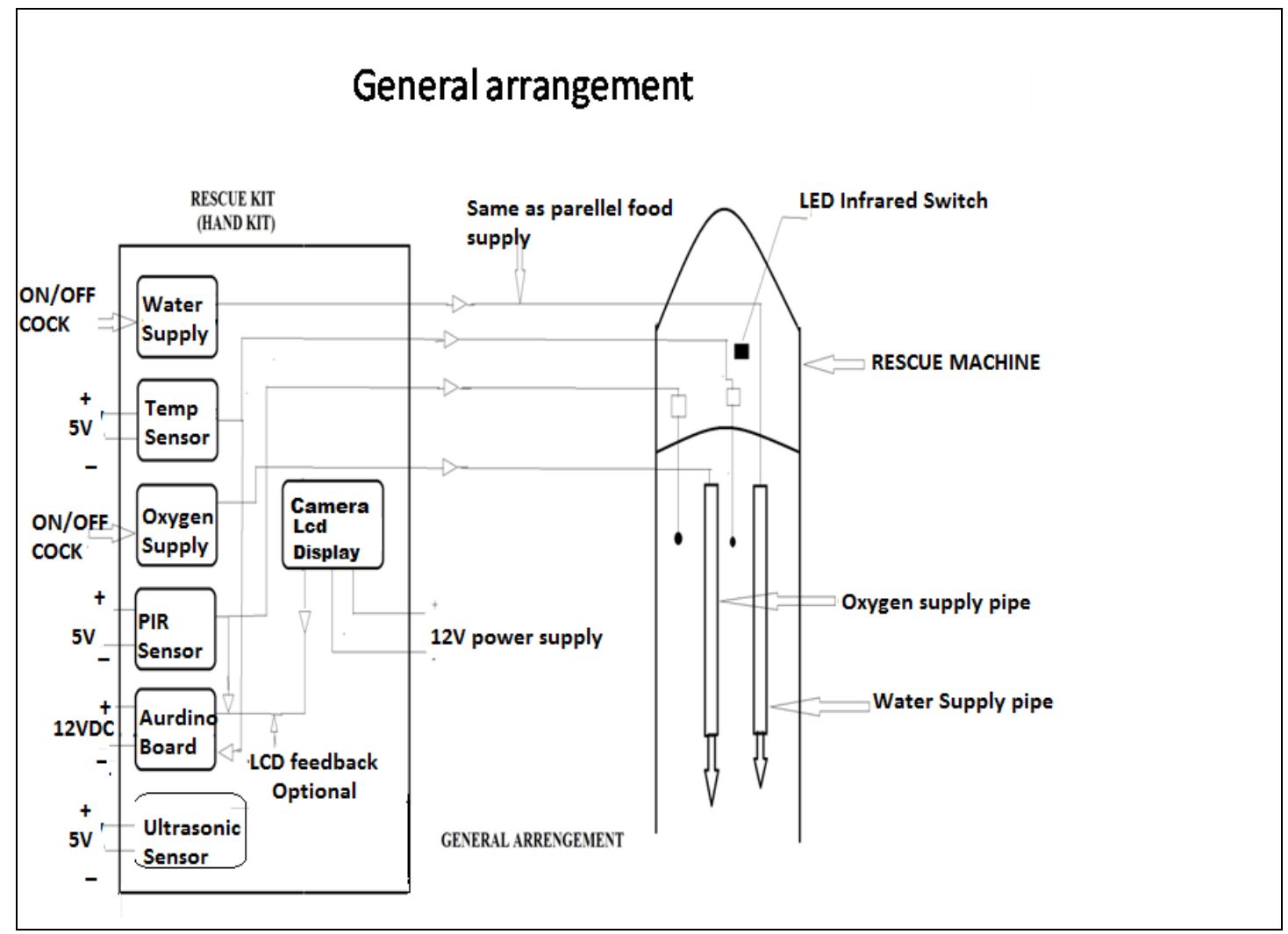

Fig-5 General arrangement for rescue kit

General arrangement for hardware architecture. Rescue machine is divide in two different part from which one is upper header which is fully human controlled machine and lower header which is totally remote controlled machine. Rescue kit is fully made in rubber form material. So it will never let fall any hazardous material over the child. It is light weight machine that can easily go down into the boar well. In this rescue machine, special arrangement for oxygen and water supply have been made for life saving purpose.

Rescue machine will divide in two different parts 1) upper header 2) lower header 1. Rescue machine upper header

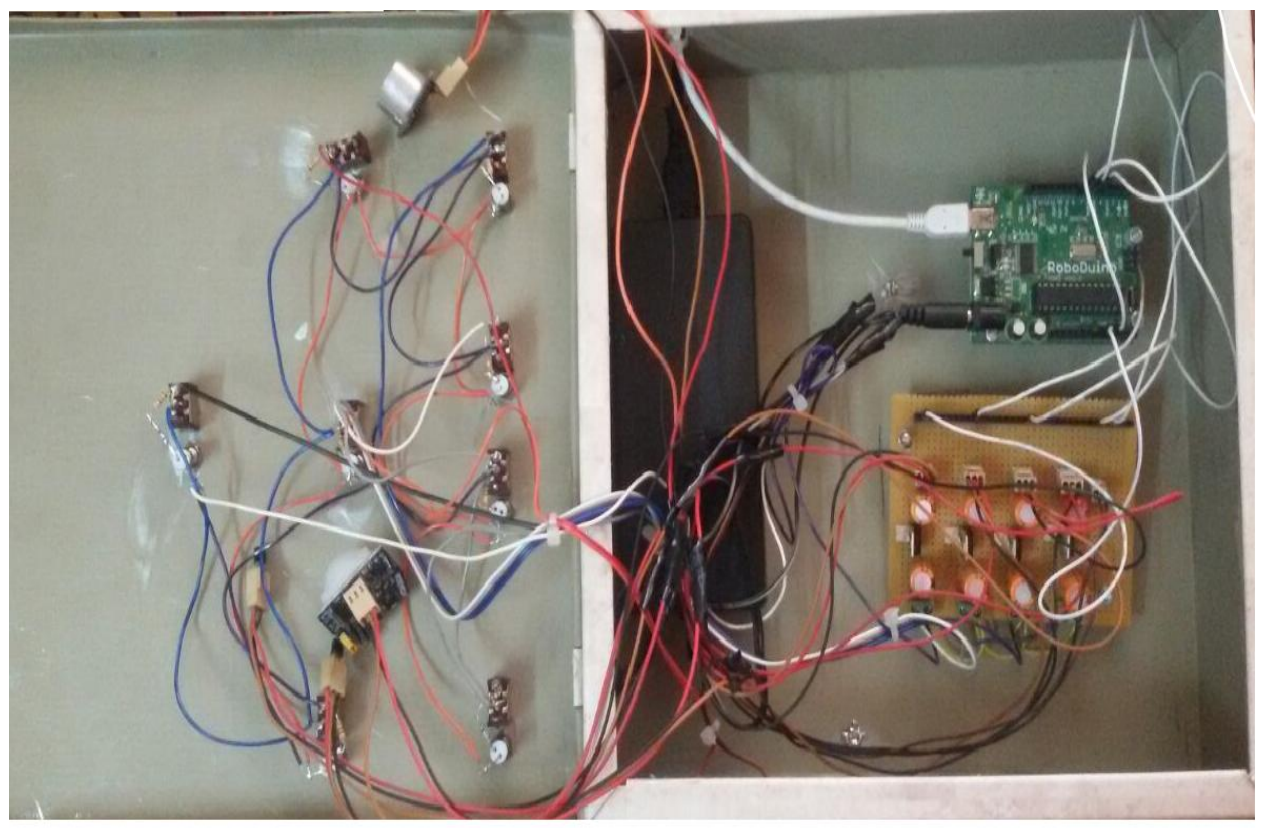

Fig-6 Rescue machine upper header 


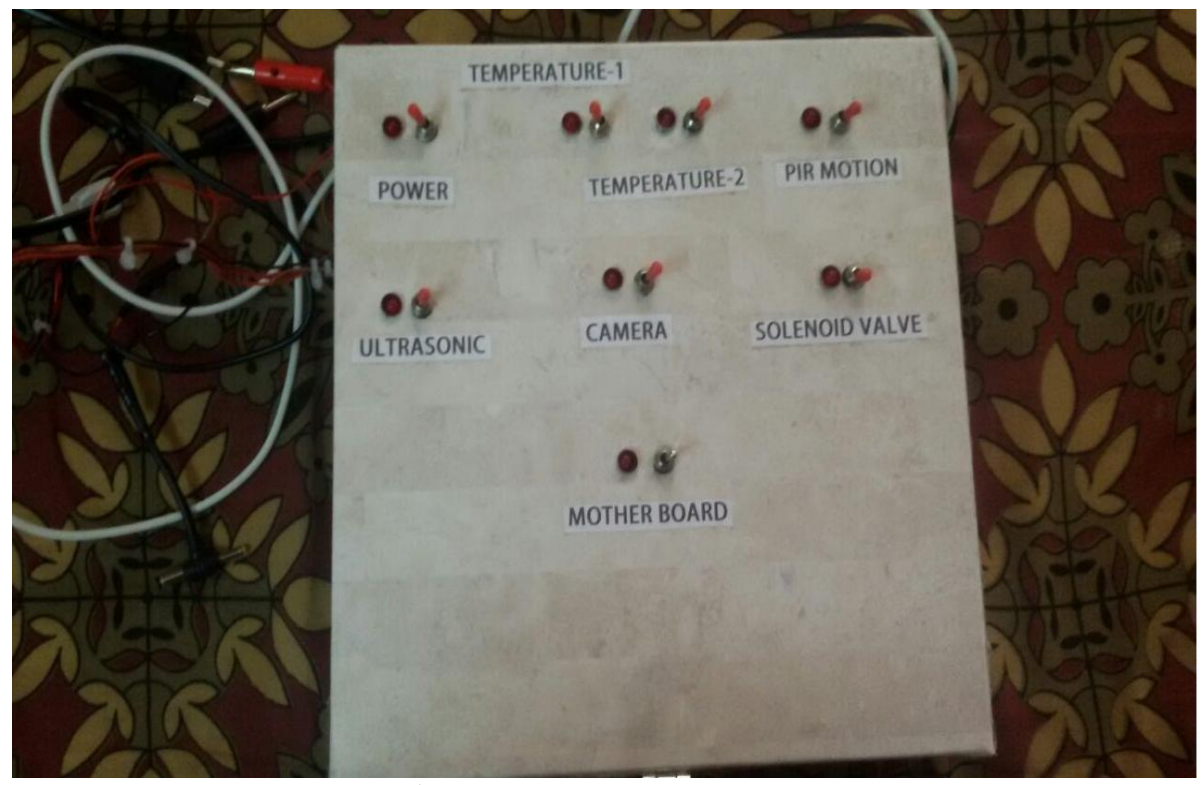

Fig-7 Front view upper header

\section{Supportive System for Rescue Model}

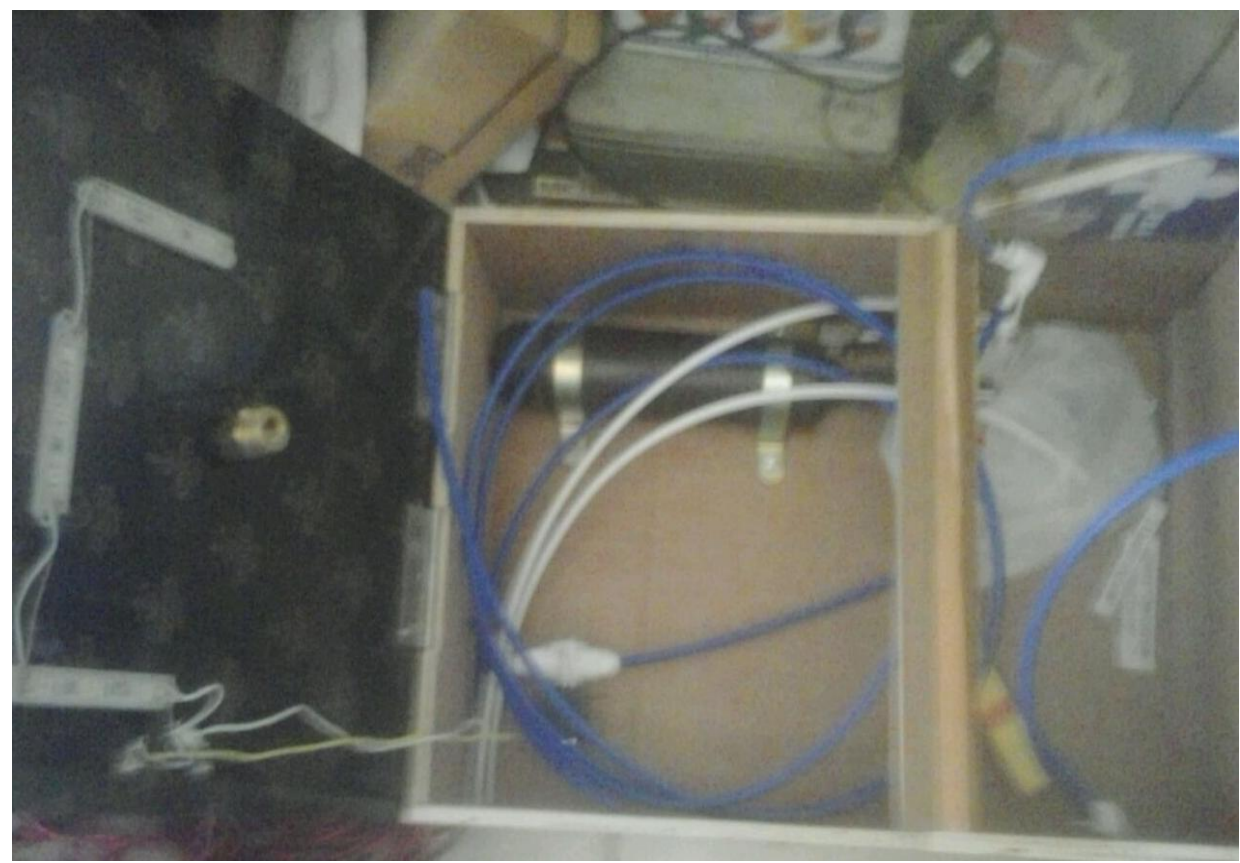

Fig-8 oxygen \& water supplying system

Upper header is fully human control machine. It will work like a panel operated machine. All the switches, valve, connector, tubes, alarm all are assemble with this upper header. All switches \& indicators are displayed in this machine.

2.Second one is lower header which are slowly going down into the boar well .This lower header is fully automate machine .this machine is assembled with infrared camera, passive motion sensor ,ultrasonic sensor ,temp sensors, one wireless mike, and assemble with oxygen \& water tubing system to save the child life.

Lower header is under progress and it will be introduced shortly. This header will be containing camera, IR LED, mike, oxygen and water supply tubes and sensors for life saving purpose. For the purpose of life saving we are going to make the machine to go inside the bore well. 


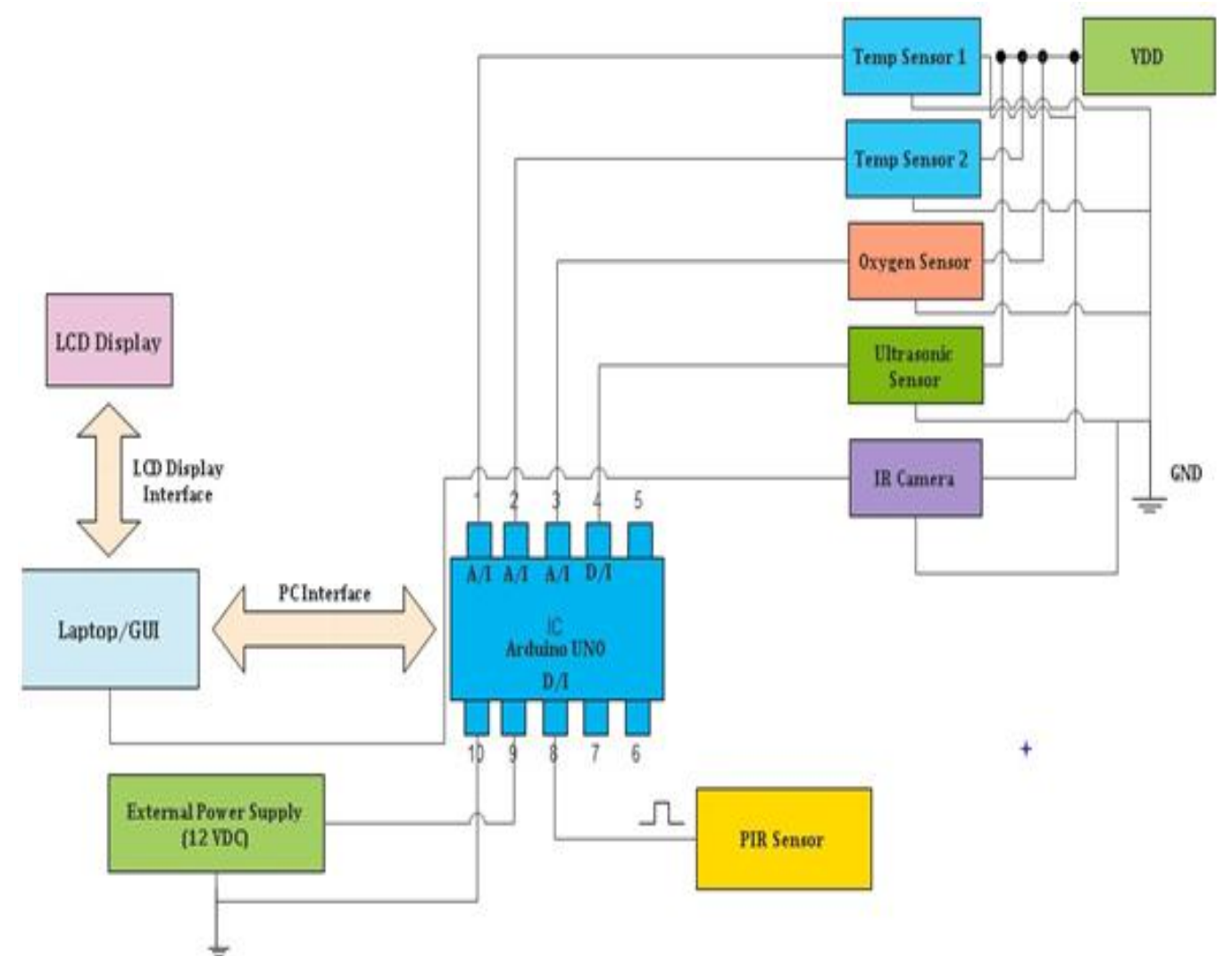

Fig-9 Block diagram sensors interface with aurdino board

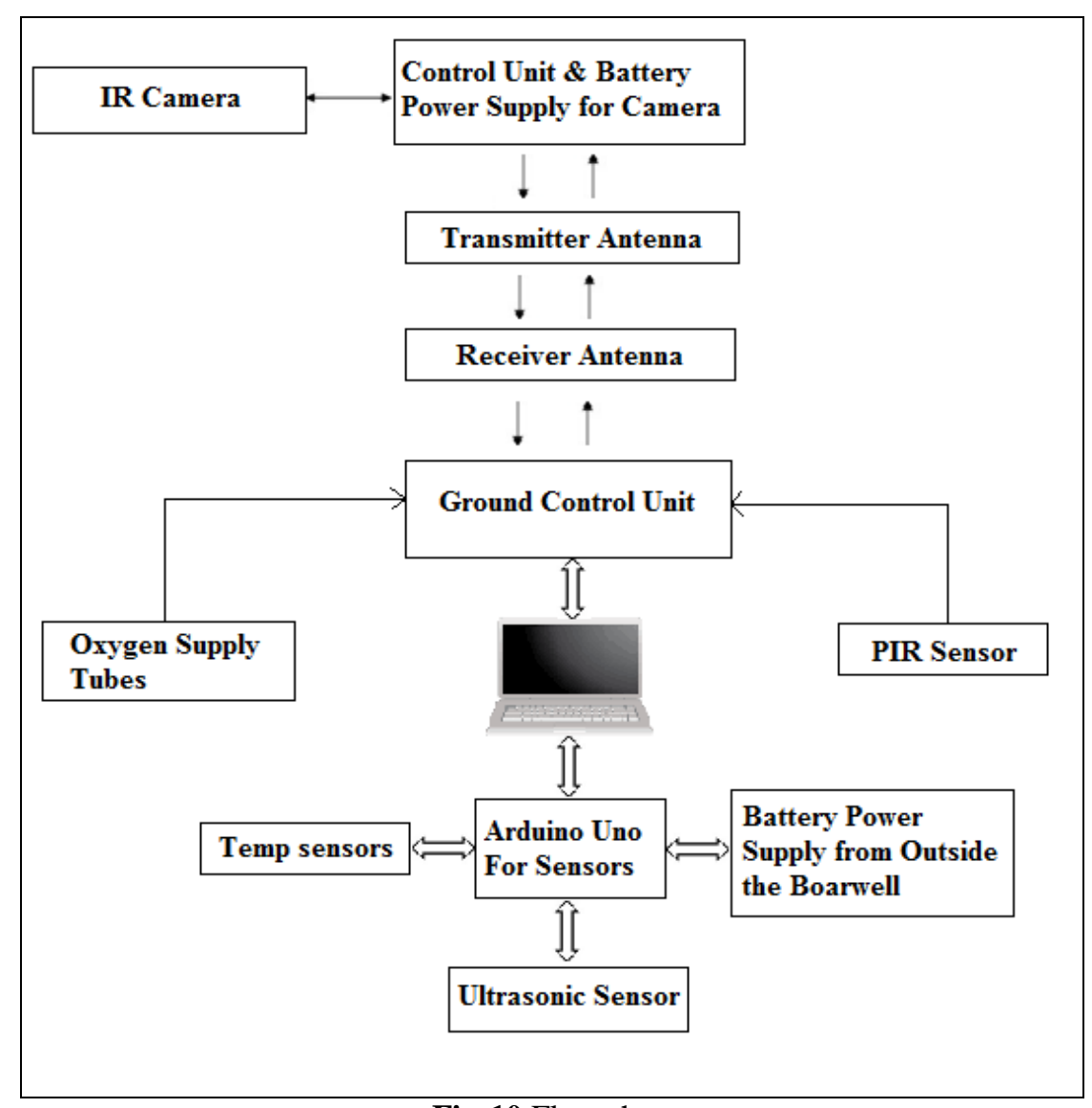

Fig-10 Flow chart

Fig-10 shows the flow chart for whole computerised control system 


\subsection{Important Component for Life Saving Model}

\begin{tabular}{|c|c|}
\hline COMPONANTS & FUNCTION \\
\hline Wireless infrared camera & $\begin{array}{l}\text { To detect and handle the positioning of the } \\
\text { baby }\end{array}$ \\
\hline Oxygen supply system & To supply oxygen to baby from the surface \\
\hline Water supply system\& food supply system & $\begin{array}{l}\text { To supply water \& glucose to the child threw } \\
\text { hoses }\end{array}$ \\
\hline DS temp sensor & $\begin{array}{l}\text { To measure temperature of the baby and } \\
\text { surroundings area }\end{array}$ \\
\hline Passive motion sensor & To measure the baby is alive or not \\
\hline $\begin{array}{l}\text { speaker \&mike system using small micro } \\
\text { amplifier }\end{array}$ & $\begin{array}{l}\text { To listen the parents sound to the trapped } \\
\text { baby. }\end{array}$ \\
\hline Ultrasonic sensor & $\begin{array}{l}\text { For measuring distance for rescue machine to } \\
\text { victim at ground }\end{array}$ \\
\hline Arduino ATmega328 & $\begin{array}{l}\text { For interface all the sensor \& controlling } \\
\text { provide of them }\end{array}$ \\
\hline 12volt rechargeable battery & To supply purpose \\
\hline
\end{tabular}

\subsection{Piping \& Instrumentation Diagram for Oxygen \& Water Controlling System}

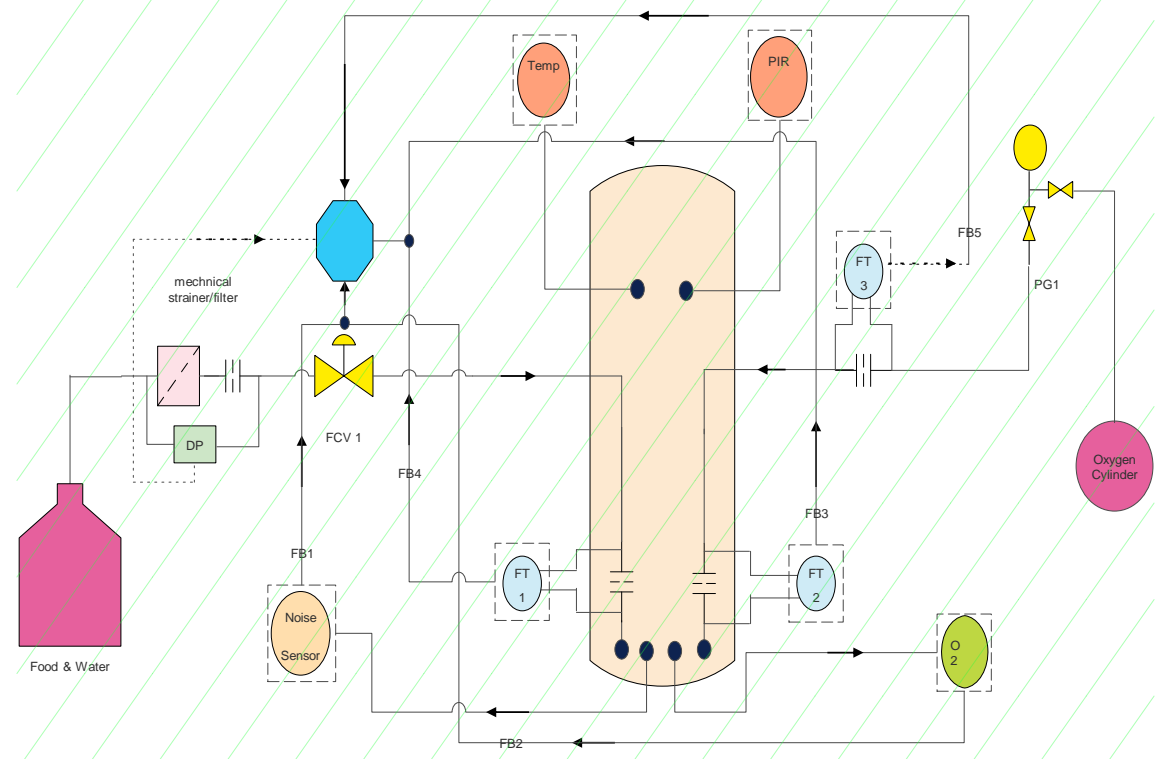

PIPING \& INSTRUMENTATION DIAGRAM

Fig-11. Piping \& instrumentation diagram

1. Brief description of the diagram, including the forward or feedback controller i.e. how you are going to check whether there is oxygen or water supply is reaching to the baby or not.

2. My objective is to provide food, water and oxygen to the trapped baby under the bore well without any affection to baby.

3. For oxygen, food and water supply I am using rubber hose pipe. I must be sure about the quantity of supply to be given to child. So to fulfil this purpose, I am using flow transmitter in inlet and at outlet for accurate flow monitoring for oxygen supply. At inlet, I am using pressure gauge (PG1) to monitor oxygen pressure. The feedback signals of this FT1, FT2 and FT3 are reported back to controller.

4. Feedback signals are represented as FB1, FB2

5. For water and food supply, I am using filter and orifice plate in series with parallel Differential pressure transmitter (DP) mounted across it.

6. The Flow control valve (FCV1) is hand operated according to feedback from flow transmitter.

7. Controller will be containing a display which will show readings from all sensors. 


\section{SOFTWARE REQUIREMENTS}

\subsection{LabVIEW Software}

- LabVIEW, as a programming language, is a powerful tool that can be used to help achieve these goals. LabVIEW (Laboratory Virtual Instrument Engineering Workbench) is a graphically based programming language developed by National Instruments. Its graphical nature makes it ideal for test and measurement (T\&M), automation, instrument control, data acquisition, and data analysis applications.

- This results in significant productivity improvements over conventional programming developing LabVIEW

- In this project, we have interfaced three different sensors, monitoring four parameters. DHT11 and Ultrasonic gives digital output while LDR gives analog output. The data from the sensor is taken to Arduino. The analog LDR output is converted to digital form. Arduino Mega 2560 has an in built A/D converter. The data received on serial monitor of Arduino is serially transmitted to LabVIEW.

- The GUI is build in LabVIEW. The serial data acquisition is one using the visa tool. The four different parameters i.e. Temperature, Level, Humidity and Light Intensity are shown graphically. Also set point can be given to parameter which in case if exceeds the set point, an LED glows for alarm purpose.

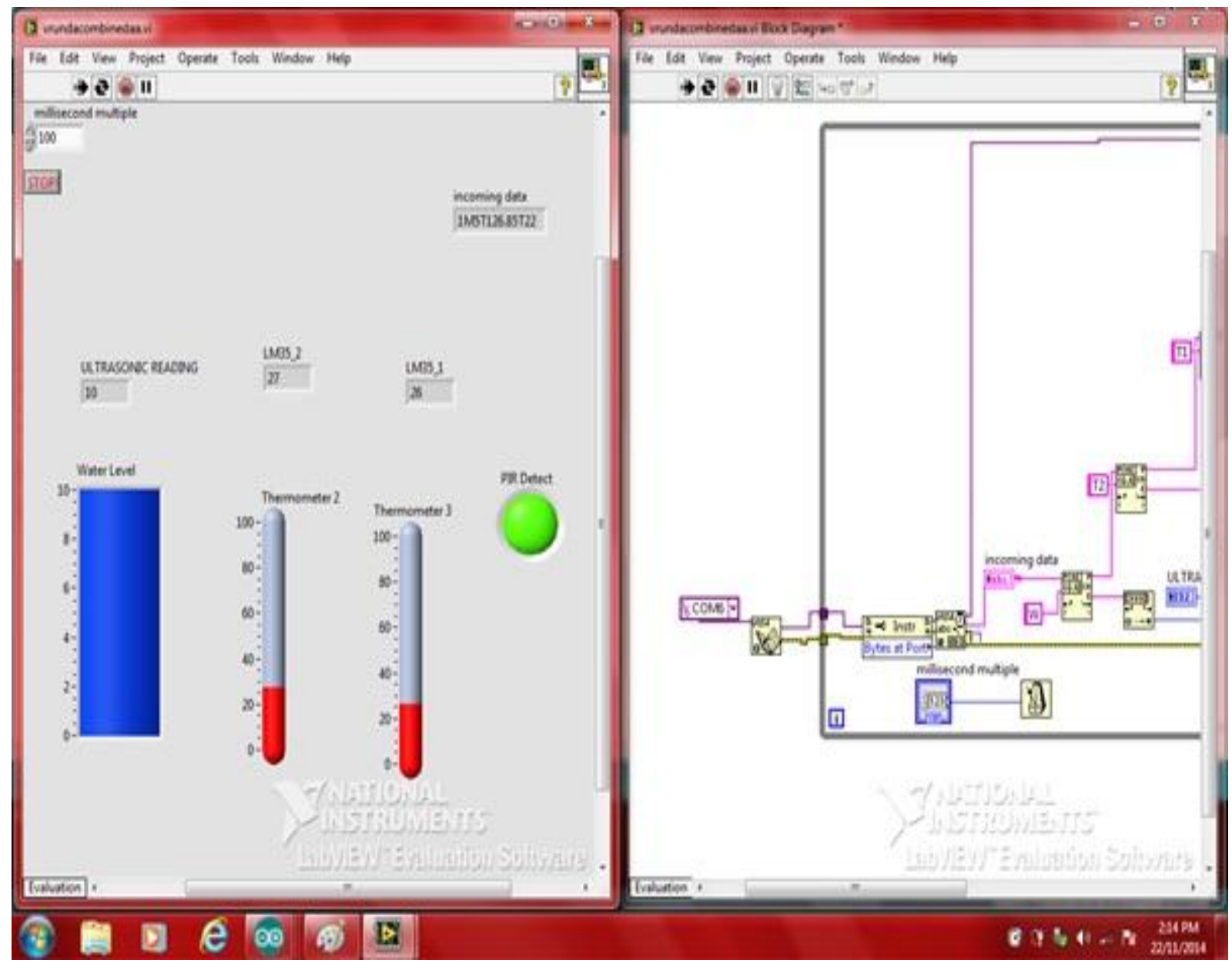

Fig-12: Final GUI developed

\section{RESULTS}

According to above report followings are result that have been achieved so far:

1. According to fig num 12 The GUI has been developed in LabVIEW software \& running successfully

2. Upper header has been prepared integrated with human control system

\section{CONCLUSION}

- Thus we tried our level best to make a partial successful bore-well rescue machine, Since the actual rescue machine cost is high, we designed in computer and we made it as model with few features excluded from the original proposed robot.

- The proposed system of rescue operation was better than ordinary rescue operation. 
- The proposed machine has several devices to do specified work which will make the robot more efficient and in safety manner.

- If we get sponsor from government or private organization, we will make the actual robot.

- $\quad$ Since the proposed model has only few modifications and more advantages, it surely improves the rescue operation with less time.

\section{FUTURE SCOPE}

- Lower header is under progress and it will be introduced shortly. This header will be containing camera, IR LED, mike, oxygen and water supply tubes and sensors for life saving purpose. For the purpose of life saving we are going to make the machine to go inside the bore well.

- The cost of rescue machine is high. But comparing to current military rescue operation, cost is less.

- The rescue operation may be declined in case of foreign bodies over the baby.

- As for long distanced operation, there may be possibilities of breaking of the gas hose or oxygen hose.

- The power transmission through wires along the rope makes the rope bulkier and it may delay the operation.

\section{ACKNOWLEDGEMENTS}

The first author thankfully acknowledges the support and co-operation provided by Dharmsinh Desai University, Nadiad, Gujarat, India and Quantum Age Solution pvt 1td, Vadodara, Gujarat, India in development of this work.

\section{REFERENCES}

[1]. 1Dr. C.N. Sakhale, 2D.M. Mate 3Subhasis Saha, Tomar Dharmpal, Pranjit Kar, Arindam Sarkar, Rupam Choudhury, Shahil Kumar, An Approach to Design of Child Saver Machine for Child Trapped in Borehole, International Journal of Research in Mechanical Engineering, OctoberDecember, 2013, pp. 26-38.

[2]. K. Saran1, S.Vignesh2, Marlon Jones Louis have discussed about the project is to design and construct a "Bore-well rescue robot" (i.e. to rescue a trapped baby from bore well), International Journal of Research in Aeronautical and Mechanical Engineering, Boar well rescue robot, pp. April 2014

[3]. G. Nithin, G. Gowtham, G. Venkatachalam and S. Narayanan, School of Mechanical Building Sciences, VIT University, India, Design and Simulation of Bore well rescue robot- Advanced, ARPN Journal of Engineering and Applied Sciences, pp. MAY 2014

[4]. B. Bharathi1, B. Suchitha Samuel, M. Tech (Embedded systems) in Geethanjali College of Engineering and Technology, Cheeryal (V), Keesara (M), R R Dist, India have discussed about Design and Construction of Rescue Robot and Pipeline Inspection Using ZigBee, International Journal of Scientific Engineering and Research (IJSER),pp. September 2013.
[5]. Prof. J .P. Ajith Kumar have discussed about Design Robot for Bore well Rescue Robot for bore well rescue offers a solution to these kind of situations,.timeis@ ficci.com.

[6]. Sakthivel. T, Sindhulakshmi.K, Bruntha.M, Radhika, ME Embedded systems and Technologies, Easwari engineering College Ramapuram, Chennai, Tamilnadu, SURVEILLANCE PRECISION USING BOREHOLE NAVIGATION ROBOT, An internatonal journal of advanced computer technology, Proceeding of 5th National Conference on VLSI, Embedded, and Communication \& Networks on April 17, 2014

\section{BIOGRAPHIES}

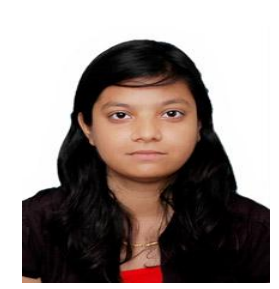

Vrunda R shah received her Bachelor of Engineering with Instrumentation \& control Engineering from government engineering college, Gandhinagar Gujarat Technological University, Ahmedabad, Gujarat, India. Her areas of interests include Automation Systems, Virtual Instrumentation and Industrial Process Control, Biomedical Instrumentation,

E-Mail: er.vrundashah@gmail.com.

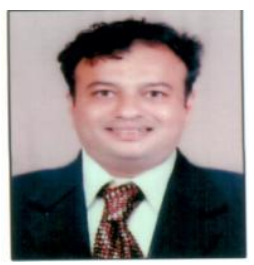

Prof. Chirag S. Dalal received his Bachelor of Engineering with Instrumentation and Control Engineering from College L.D Engineering, Ahmedabad and Master of Engineering with Instrumentation and Control Engineering at Indor, India .his area of interest is power electronics.

E-Mail:chiragsdalal@gmail.com

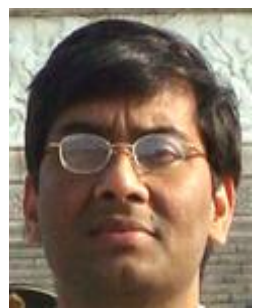

Rajeev Dubey (M. Tech. - IIT Kanpur, 1993), Managing Director, Quantum Age Tech Solutions Pvt. Ltd Experience: 20 years, Noise and vibration simulation, measurement and control.

E-Mail:rajeev@qagetech.com 